\title{
Evidence of Professional Learning: a Closer Look at Development in Practice
}

\author{
Margaret Mackay, The Business School, University of Portsmouth, UK
}

\begin{abstract}
This article considers the impact of an evidence-based approach to professional development. For the human resource field, an international trend for evidence can reinforce credibility and better professional recognition. The research focused on practitioner experiences of what counts as acceptable evidence of learning. Findings suggest that most practitioners attempt to fit learning to organizational expectations, but a quantitative view of evidence can restrict the possibilities of autonomous professional growth. Some records capture the significance of thinking around work experiences which build professional judgement. A practice implication for educators, policy makers, and employers is to widen understandings of valid evidence of learning; to value deeper reflections on casework based in practice. This article offers an approach to meaningful evidence that guides practitioner competence in the management of unpredictable workforce issues.
\end{abstract}

Key Words: evidence, professional learning, CPD, identity, HR practice, development

\section{Introduction}

A prominent international trend across occupations is the use of records to evidence professional learning (Morrell \& Learmonth, 2015; Volles, 2014). This article considers the impact of an evidence-base record on human resource (HR) practitioners' development. The challenge of talent management across multinational workforces has increased industry demands for greater professionalization of the HR field. However, the status of the HR function is often marginalized in organizational structures; an underdog position compared to more established groups, such as accountancy (Wright, 2008; Mackay, 2015b). For HR specialists, a record that demonstrates competence offers an opportunity to improve professional recognition (SHRM, 2007; XpertHR, 2016). The study examines HR practitioners' response to the demand for evidence of professional development. Findings suggest that institutional views of learning may restrict professional growth. This can undermine the potential learning value of unexpected social interactions and reflection on practice experience. This study draws attention to a prevailing industry view of evidence as quantitative, measurable outputs (CIPD, 2012). Consequently, there is a risk of learning becoming a corporate exercise, or devalued product, to satisfy narrow measures of performance (OECD, 2010). Records that candidly reflect on dynamic experience guide practitioner skill development far more than a mechanical exercise. To this end, the paper argues for an inclusive view of evidence that values the examination of practice for professional growth. The study offers three practical implications: the impact of conscious reflection, the relevance of practice insights on professional development, and the significance of an independent voice to influence individual and organizational behaviour.

A global trend in education is to measure evidence of learning; as Morrell and Learmonth (2015) remark: "governments and research funding agencies across the globe are more and more mandating evidence-based knowledge" (p. 521). The professional associations have followed this 
trend by standardizing templates to record evidence of continuing competence. Learning records attest to practice standards of integrity and professional behaviour. To investigate practitioner experiences of documenting evidence, the research is structured around two questions: What is the value of a record of professional development? What counts as evidence of learning activity?

The literature reveals a focus on the activity of continuous professional development (CPD) but scant attention to theory (Kennedy, 2014). McCormick (2010, p. 407) asserts: "CPD needs to be theorized more ... and a range of perhaps competing theories would make for a healthier field". In response to these calls, this study examined how an evidence-based framework influences understandings, or conceptual views, of CPD. To begin the demand for evidence of learning is reviewed together with the reason HR practitioners specifically want to prove their competence. Then the complex nature of people management expertise is considered, the tensions of practice and the learning opportunities shaped by power relations at work. Finally, the implications for practice are discussed as to what represents evidence of professional learning; development as a quantifiable output or development as a process of evolving skills.

\section{Evidence of professional development}

Professional development is seen as a quality assurance measure that regulates competence to practice (Boud \& Hager, 2012). Taylor (2009) argues that knowledge development and continuous innovation increase the economic value of human capital. Organizations therefore have an economic interest in frameworks that audit professional learning. Research by the Confederation of British Industry (CBI, 2015, p. 11) shows managers expect their employees to be engaged in: "a continuous lifelong process through which skills are regularly upgraded to adapt to fast-changing environments". The evidence of competence improvement can be pictured as a measurement bar which is: "constantly being raised by international competition, technical change and customer demand" (CBI, 2015, p. 24). Gao and Riley (2010, p. 318) claim this need for evidence applies to multiple professions:

the personal need of the professional for integration in the workplace creates a situation whereby the expert needs to demonstrate professional competence to fulfil the expectations of their colleagues and of the image of the professional body.

An evidence framework of continuing competence also satisfies stakeholders of professional transparency and accountability.

In the case of the HR function evidence is increasingly linked to a claim to advance professional recognition. Wright (2008, p. 1066) asserts: "to gain legitimacy as experts [HR] they must demonstrate to senior managers how their expertise contributes to organizational goals". Situational knowledge is central to professional expertise. As Gao and Riley (2010, p. 328) point out: "the individual needs to feel a sense of security in the rightness of judgement". This professional judgement is the ability to apply theoretical knowledge to active practice; to transfer knowing into doing. For HR practitioners documenting evidence of a professional self resonates with the literature on work identity. Brown (2014, p. 29) asserts a globalized labour market increases the pressure to demonstrate a professional image:

For professionals caught in ever more intense competitive work situations ... insecurities about the self are an omnipresent and sometimes all-consuming aspect of their identity work. 
Such insecurities about a professional identity increase for HR specialists when regarded as an organizational underdog (Wright, 2008). So, an evidence-base of competence provides an anchor to assert professional identity in context (Mackay, 2015a; Brown, 2014). The Chartered Institute of Personnel and Development's Code of Professional Conduct (1 July 2012) sets out the obligations of professional standards to uphold the reputation of the HR profession. An XpertHR (2016) cross-sector survey of HR roles and responsibilities, with 535 respondents, explains how an international trend to gather evidence can support better professional recognition:

there is a move to gather, measure and analyse data in order to improve overall performance of both HR and the organization, but also to demonstrate the value of the HR function.

This survey shows that evidence matters to the credibility of the HR field and reinforces a professional identity. Guidance on CPD activity emphasizes the value of continuous learning to job security, employment prospects and professional respect. The professional bodies urge practitioners to emphasize the visible results of CPD achievements to polish their credentials (CIPD, 2012; SHRM, 2007). But a view of learning as tangible outputs can reduce professional development to the counting of workshop attendance hours or online tasks completed. Thomson (2001, p. 249) argues such thinking "quantifies all qualitative relations". In short, it frames learning as what can be measured. This creates a tension in evidence of learning as improvements in soft skills and professional judgement are not easy to quantify. Yet HR requires adaptive, social and relational skills to manage changing situations.

\section{People management expertise}

HR specialists need professional competence to be able to influence line managers, facilitate staff productivity and steer organizational practice in line with ethical values. Situations of staff recruitment, retention and performance management often involve tough decisions to secure trust and respect across the workforce. Table 1 illustrates the challenges of HR operating practice set next to the standards of professional behaviour.

\begin{tabular}{|c|c|c|}
\hline $\begin{array}{c}\text { Practice } \\
\text { HR specialists' concerns }\end{array}$ & $\begin{array}{c}\text { Practice } \\
\text { Employees'concerns }\end{array}$ & $\begin{array}{c}\text { Policy } \\
\text { Code of Professional } \\
\text { Conduct }\end{array}$ \\
\hline $\begin{array}{l}\text { Favouritism in hiring, } \\
\text { training, and promotion } \\
\text { decisions }\end{array}$ & Low trust in senior managers & $\begin{array}{l}\text { Promote equality of } \\
\text { opportunity }\end{array}$ \\
\hline $\begin{array}{l}\text { Inconsistency in disciplinary } \\
\text { measures }\end{array}$ & Lying to employees & $\begin{array}{l}\text { Demonstrate and promote } \\
\text { fair and reasonable standards } \\
\text { in treatment of people }\end{array}$ \\
\hline $\begin{array}{l}\text { Failure to maintain } \\
\text { confidentiality of customers } \\
\text { or employees }\end{array}$ & $\begin{array}{l}\text { Pressure to compromise } \\
\text { standards }\end{array}$ & $\begin{array}{l}\text { Safeguard all confidential, } \\
\text { commercially-sensitive, and } \\
\text { personal data }\end{array}$ \\
\hline $\begin{array}{l}\text { Potential discrimination in } \\
\text { appraisals and in allocating } \\
\text { pay/non-pay reward }\end{array}$ & $\begin{array}{l}\text { Failure to discipline or } \\
\text { punish bad or abusive } \\
\text { behaviour }\end{array}$ & $\begin{array}{l}\text { Challenge others if they } \\
\text { suspect unlawful or unethical } \\
\text { conduct or behaviour }\end{array}$ \\
\hline
\end{tabular}

Table I: Adapted from IES 2015 Ethical dilemmas in HR practice \& CIPD Code of

Professional Conduct 2012 
These challenges make clear that HR expertise evolves through situational knowledge and people management experience. Expertise is based on the application of independent judgement and impartial professional advice. For example, practitioners require nuanced skills and up-todate understandings of employment law to ensure due process: "a dismissal will be unfair if the decision to dismiss an employee is improperly influenced by the HR department" (www.xperthr. co.uk). This highlights the need for fine-tuned development of skills which Hart and Montague (2015, p. 46) describe as: "an evolution of complexity, something that develops incrementally".

\section{Learning shaped by power relations}

Individual development and organizational agendas for learning appear to be of mutual benefit; employers need knowledge currency for human capital advantage and individuals can improve their career prospects through learning (Garofano \& Salas, 2005). However, Contu and Willmott (2003, p. 284) contradict this outlook saying: "learning practices are shaped, enabled, and constrained within relations of power". This means managerial favouritism through powerful players can fast-track or restrict access to learning opportunities. Coles $(2002$, p. 8) reasons that ongoing learning needs support and structure but: "as little direction as possible" to develop professional judgement. Fixed organizational targets may inhibit wider, informal or spontaneous development. In higher education, Clegg (2003, p. 48) observes that for professional development "the balance has shifted decisively to institutional agendas". Similarly, McWilliam (2002, p. 290) notes: "In universities, professional development activities provide scripts for turning ourselves into better (more professional) academics". An organizational insistence on employee ownership of development overlooks the dimensions of power relations. Coffield (1999) declares the emphasis on personal responsibility, or "self-regulation" in a labour market, places the burden for development on individual practitioners. This self-directed approach can absolve employers from any responsibility for strategic investment in workforce development. It can also favour a managerial view of learning as predictable target outcomes. An HR specialist may feel obliged to follow an organizational script that aligns with business priorities. The problem is that in conforming to organizational norms, the number of training courses logged may become a substitute for meaningful competence improvement. As McWilliam (2002) declares:

evidence of diligent attendance and participation is now available to be read as a key indicator of "quality" academic performance (p. 296).

This means that practitioner efforts to advance their learning may be confined by organizational power relations.

\section{Incremental learning as professional growth}

Professional formation is a complex process of incremental learning to adapt to specific cultures and practice situations. Eraut (2004) declares profound learning development often stems from reflection on failures, or unexpected challenges. In this study, HR specialists faced unexpected demands flowing from the UK's vote to leave the European Union (known as Brexit); workforce concerns have spiralled over job insecurity and ambiguous fears of xenophobia (IES, 2016). HR specialists often make use of professional community networks: "as a form of 'emotional support' and [to] discuss new techniques and research" (Wright, 2008, p. 1080). This type of social learning across the broader HR community is unlikely to feature in organizational targets. Still, research demonstrates that informal social learning is often more significant for professional 
growth than the acquisition of formal training credits (Boud \& Hager, 2012). As an example, Wright's (2008) research with 33 HR managers in Australia reveals the use of influencing skills to develop more credibility in the organization. One respondent:

emphasized how her learning and development group were now positioning themselves as "a trusted adviser versus just being their HR person" (p. 1073).

A development record thus encourages a retrospective view of HR work as a long-term strategic craft of nurturing organizational relationships. Continuous improvement assumes a capacity for learning as a reflective practitioner (Hart \& Montague, 2015). Morrell and Learmonth (2015, p. 530) insist that fundamental to management learning are: "pluralism, critical reflexivity, questioning of basic assumptions, intellectual flexibility". In other words, learning is wide in scope with multiple dimensions that make use of reflection on experience to notice new understandings and scrutinize formulaic responses to discover a better course of action (Mackay \& Tymon, 2014).

To summarize, people management expertise requires flexible, adaptive development to master complex professional skills. Evidence of continuing competence can demonstrate the value of the HR function and validate aspirations for better professional recognition. Yet a view of evidence as tangible outputs creates a tension in attempting to quantify small steps in skills development. Business leaders regard learning development as an individual responsibility to improve human capital for competitive environments. But existing power dynamics can affect individual access to learning opportunities within a hierarchical structure. What follows is an explanation of the research design and data collection to explore these issues in HR practice situations.

\section{The Research Study}

There is growing interest in evidence-based practice across diverse professions including education and human resource management (Volles, 2014). Researchers, therefore, have a responsibility to examine policy frameworks to better understand the impact on individual behaviour in practice. The work of HR affects staff morale, motivation, and organizational effectiveness; what happens in practice carries more weight in an organizational context than policy guidance from professional associations.

A research approach to examine the dynamic of practice, termed a phenomenological method, puts practitioner experience in the spotlight. The practice of HR is based on competence and effective work relations formed through social interactions (Wright, 2008). By focusing on the process of social construction in practice the study considered a dominant view of evidence as tangible outputs (Thomson, 2001). This is not to say that an evidence-based policy works against learning in practice but rather to explore practitioner understandings of acceptable learning. Theory needs to impact on policy and practice to gain a better understanding of the realities of professional development (Kennedy, 2014). In short, what counts as evidence of professional development? The research aim to gather practitioner views used focus group discussions and purposively selected learning records. Focus groups were deliberately chosen to replicate practitioners' informal development and social learning from community networks. Qualitative data offer rich accounts of lived practice experiences in organizational life (Cunliffe, 2010) and facilitate conceptual views of professional development. 


\section{Method Section}

First, a close reading of professional associations' policy codes analysed frameworks of development (e.g., CIPD, 2012; SHRM, 2007). The secondary data set out three core principles: continuing competence, improvements in HR practice, and commitment to advance the field of human resources. This confirms a policy stance of learning as currency: individual improvement, workforce development, and gain for the HR professional community. Second, research participants were invited from three separate cohorts across two collaborative UK university campuses. The sample included 45 practitioners and managers enrolled on a postgraduate study in human resource development. Participant data was collected in two complementary strands: peer group discussions and a sample of documented self-choice records from 32 volunteer participants. Focus group clusters of 4-6 participants discussed three topics guided by the research questions: the role of an evidence record; perceptions of relevant learning; and the link to professional competence development. The focus groups were held on three separate days and a note-taker captured discussions that spanned 25 to 40 minutes. Self-choice records are one element of a learning portfolio and practitioners write about any aspect of development in professional learning, hence the justification for the analysis of these records.

The coding followed a systematic process of reading and re-reading the collected data, identifying descriptive codes, and then recognizing pattern associations to categorize responses. The analysis compared the small detail of applied practice with an overview, more holistic conception of professional learning. The researcher identified five principal categories: use value of evidence record; selection of learning; fit for institution; work of HR specialist; identity challenge. This small-scale study has several limitations: practitioner accounts are self-reports and therefore subjective in selecting relevant experiences. How we interpret an experience depends on a unique viewpoint. We may assume that good practice in the HR field is to document meetings and notes but organizational demands for action may crowd out this effort. A record of evidence thus places more value on the continuous process of learning and professional development. In addition, individual work contexts vary and this may affect whether a record attempts to emphasize personal accomplishments or conceal flaws. However, the study can enhance our understanding of an evidence-based approach to learning and challenge a dominant view of quantitative evidence. Also, accounts of organizational experiences highlight the benefits and constraints of evidence on professional growth. The participants were mature HR practitioners, working towards advanced qualification, and as such represented a range of public and private sector organizational contexts. Accordingly, this qualitative study offers fresh insights into operating practice that guides HR practitioners' professional growth. A future avenue for research is to investigate industry perceptions of the HR function's advance in professional status.

\section{Data Presentation and Findings}

First, data from the focus group discussions are presented on participants' attitudes to the value of an evidence record. Then three key themes from the learning records are presented: the need for organizational fit, an image of competence, and reflections on HR practice. 


\section{Does a record matter?}

Most participants explained how a written record of CPD activity kept them focused on career development and strengthened their confidence in professional capabilities. More than a third saw the record of evidence as a way to ground professional identity:

I like to draw on and take comfort from my years of work experience to draw parallels with what I am learning to practical application in the workplace. Continuing my personal development helps me put aside thoughts of others' opinions and focus on the job I am doing.

The comment 'others' opinions' alludes to difficult cases of HR practice that test professional competence. It also confirms the need to develop professional judgement that is respected, rather than popular, in a workplace context (Gao \& Riley, 2010). Writing a record gives retrospective clarity on the learning potential of everyday practice:

Through my professional development record, I have become more aware of the difference I can make to my workplace and the opportunities available for me to get involved. As an HR Assistant in a busy outsourcing environment it is easy to forget the amount of exposure to employment relations situations I have every day.

Gaining credibility by demonstrating HR competence in practice was a recurring point in discussions. At least one quarter were concerned that workload and time pressures hampered the regular recording of learning. One practitioner contrasted the policy guidelines of record keeping with the actual practice of spontaneous conversations:

I do believe in the benefits of this exercise, without it, it can be difficult to develop. However, when exhaustion levels are high and time is short, it is better to talk with someone briefly or just go over it internally.

Some participants perceived a disparity between formal system requirements for records and actual implementation in context:

CPD is the behaviour, application, and confidence to test skills, the resilience to accept when a situation goes wrong and the risk taking required to alter your approach ... it's that process of how do you do it, not how do you record it.

More than half of the group discussions remarked on work learning as frequently haphazard but evidence records assume a chronological narrative: "CPD is often perceived as 'paid' training and in-house opportunities are overlooked". This echoes McWilliam's (2002) view that scheduled training events are convenient to recall as trackable results. The discussions were wide-ranging but given the study's focus, three prominent themes from the learning records are presented next.

\section{CPD to fit institution}

The records revealed that two-thirds of HR practitioners perceived professional learning as shaping oneself to the organization:

By developing my skills and knowledge, with the aim of tailoring myself to different aspects of the business, this increases the value I can offer to the company and enhances my professional development.

This indicates the emphasis on human capital in adapting to business priorities. Some voiced concern about HR's visible impact: 
I am unsure of the HR department's strategy - I cannot see how it fits within the wider organization as a value adding tool. If I am unable to understand the requirements of the organization and link to areas of personal development, I may not pursue the appropriate avenues of CPD.

This underlying concern increased practitioner attempts to align learning to the business. Practitioners voiced the dominant industry and managerial view that employees are responsible for their own development. Another interpretation is that concerns over job security increase a mapping to business goals (Garofano \& Salas, 2005). However, several practitioners pointed to the risk of managerial disinterest in development:

Not only has the employee got to be committed to CPD, management need to support it. At my workplace we are expected to continually develop within our role. If the employee isn't proactive, managers don't tend to encourage development.

This adds to Contu and Willmott's (2003) view that inherent power relations affect development opportunities. Diverse organizational cultures and line managers will vary in their explicit support for individual development.

\section{An image of competence}

Strikingly, most learning records claimed progress results:

Due to my growth in confidence and understanding as an HR practitioner, I am able to justify my proposals and gain credibility from stakeholders.

This contrasted with the group discussions where peers expressed doubts about noticeable learning outputs. HR specialists, as discussed above, are keen to position themselves as credible business partners (Mackay, 2015b). Accordingly, individual memory can construct a coherent image of growth:

As I am early on in my HR career, I also wanted to use the course to instil in me a mind-set of creativity and development that I can use as a foundation for personal development.

The record enables practitioners to see themselves as professional experts through a social construction of identity. By contrast, only one fifth of records mentioned developmental struggles; as if this suggested a learning failure or a character flaw. One wrote:

I have found the reflective learning process extremely difficult, which has disappointed me personally. I thought that with my practical experience I would have little difficulty associating my learning in work. I was stuck in my ways, a product of the regimented environment I have become used to.

The effort to demonstrate acceptable evidence of tangible learning can narrow perspectives of professional development and put little value on learning in and through work.

\section{Reflections on practice}

HR specialists need soft skills to influence line managers and deal with workforce expectations of service (IES, 2015). Few records captured the gradual, incremental progress of building skills and expanding understanding. However, one fifth, noted observations on human behaviour and psychological insights which can expand professional judgement (Hart \& Montague, 2015). Briefly, two examples illustrate a fine-tuning of skills, thinking over experience in qualitative reflections, that build HR expertise. 
Case One: Coaching a line manager through employee dismissal

A practitioner reflected on the unpredictable behaviour of both the manager and employee:

I was apprehensive about the employee's reaction prior to the termination of employment meeting because I was unable to predict what it would be. I challenged the manager constantly to ensure they had specific, relevant examples and offered alternative solutions to dismissal, including performance management. I had prepared a script for the manager to use as a guideline and reassured them that I would assist with the delivery, if required. This was the first time the manager had delivered this type of message and I was able to coach them through the meeting with confidence.

This conscious preparation to coach the line manager, challenge background assumptions and treat the employee fairly increased the HR practitioner's skill in a tense situation. Such professional competence encourages the trust of both the manager and the employee. The learning experience then becomes a guide for future refinement of employee relations skills. This matters to HR practice as reflection on experience teases out the significance of casework to deepen professional competence.

Case Two: HR ensuring fairness in selection process

Another participant realized the impact of unconscious bias:

The recruitment manager had run so many assessment centres that she had got to the point where the repetition of this routine had overtaken her judgement. She was deciding to put a candidate through who had failed the compulsory numeracy test because she like their personality.

This reflection on organizational practice steers the HR specialist to question managerial bias in the treatment of candidates. These examples illustrate a scrutiny of relevant work situations that enlighten and guide practice. Professional growth is based on these contextual realizations that build skills, judgement and expert decision-making.

\section{Discussion}

Evidence of professional learning is critical for HR practitioners in demonstrating continuing competence. This article explores the quality of evidence that supports growth in professional judgement, situational knowledge and skills. The next section summarizes the study findings and discusses the implications for practice.

\section{Value of evidence}

Findings indicate that HR practitioners appreciate the value of evidence to underline professional credibility and trust in working relations. A majority noted that evidence reassures stakeholders of adherence to professional standards. The record therefore provides a structure for professional growth; an opportunity to look back and learn from practice experiences. Much HR work depends on complex, ambiguous workforce issues that demand soft skills such as judgement and influence in practice. How can these soft skills be evidenced? Thomson (2001) argues that an emphasis on quantifying learning, what we can easily measure, detracts from the importance of professional learning. The pressure to document evidence can lead practitioners to fall back on formal training events and ignore the significance of reflection on experiences. In how we think about evidence, as a conceptual view, Morrell and Learmonth (2015, p. 529) warn: 
an "evidence-based" rhetoric is inexorably tied up with a reductionist and exclusionary model of what counts as knowledge - as much in management studies as in other disciplines.

Put simply, a perception of acceptable learning as tangible can confine development to measurable activity, such as hours of workshop attendance. This view of evidence may close off unexpected interactions; the serendipitous learning in everyday practice that expands professional judgement and decision-making (Eraut, 2004). Several practitioners experienced a dissonance between a mechanical record system and the haphazard social nature of workplace learning. A dominant view of evidence is based on scientific knowledge which evaluates learning as measurable outputs, in research terms known as positivism. For example, the number of formal courses attended, the hours clocked in CPD, or the budget spent. Formal qualifications undoubtedly remain as key features of initial professional formation. Still, convincing evidence of learning is seen in qualitative case reviews, work group discussions and reflections that distil the meaning of practice. These cumulative learning insights are built through workplace interactions that feed longer-term understandings of social behaviour, in research terms social constructivism. This implies that a wider view of evidence appreciates social learning and experimentation in practice to expand situational judgement and skills.

\section{The power relations implicit in learning records}

A record of evidence is also an opportunity to demonstrate HR competence which backs recent campaigns for better professional recognition (XpertHR, 2016). The data indicate a majority of practitioners present a fully competent professional self. Paradoxically, this notion of the 'finished' professional implies a stoppage of growth or development stasis. Whereas the development of knowledge, professional judgement and practitioner wisdom is a continuing work in progress (Hart \& Montague, 2015). An image of complete competence, endorsed by training programmes, suggests a need to satisfy stakeholder expectations and conceal skill gaps or learning anxieties. Consequently, most records focused on development in line with organizational priorities rather than learning from situational understanding. Few practitioners looked for managerial support in professional development despite the hierarchical power of managers in providing, or restricting, learning opportunities (Contu \& Willmott, 2003). This begs a question: in sticking to an organizational development script, does a practitioner reinforce existing power relations that possibly contribute to a marginalization of the HR function? An implication is that practitioners need to consciously maintain an independent voice to challenge bias, or unfair practice, as directed by the professional standards.

\section{An HR voice for collective progress}

Business leaders say they want an HR function with an independent voice (IES, 2015); capable of strategically balancing management concerns and employee productivity. Global business pressures on managing talent have increased the demands for greater professionalization in the HR field. For instance, the UK's Brexit vote has created extreme turbulence for HR in managing workforce concerns around job security, mobility, and direction. Practitioner development is an evolving, qualitative process of interpreting social behaviour to advise and coach line managers through hiring, performance, and retention decisions. Critical reflection on experiences can cultivate adaptive skills to influence organizational practice (Mackay \& Tymon, 2014). Records can capture gradual development of insights into behaviour and self-awareness. Significantly, the findings illustrate that reflections on disciplinary and recruitment cases deepen behavioural 
understandings to guide effective application. The practice implication is that reflective learning can create thinking space for practitioners to manage diverse people and performance issues.

\section{Implications for Practice}

To summarize, this study offers three practice implications:

1. First, a learning record acts as a support structure to distil critical insights into experience which deepen knowledge and skills. Practitioners need to consciously develop professional independence and be mindful of institutional constraints.

2. Second, HR educators need to reframe evidence of learning as wider than tangible outputs, such as the number of training courses completed. We need to value reflections on casework as convincing, qualitative evidence of expanding professional judgement.

3. Third, learning records create thinking space for HR practitioners to hone an independent voice capable of challenging unfair treatment and promoting equality. Further professional associations, industry watchdogs and government agencies need to emphasize employer responsibilities for investment in staff development.

To conclude, this study illustrates the importance of professional learning for the shifting complexities of HR work. HR specialists deal with critical issues of talent management and they need up-to-date expertise to act in uncertain work situations. The benefit of evidence reinforces practitioner credibility and professional recognition. A practitioner record can capture insights from case notes, social interactions, and developmental thinking around actual practice. This is meaningful evidence that respects the profound learning of casework to adapt to unpredictable people issues. To be adaptive experts we need to stay open to learning; ever curious in our approach in a range of contexts. This article challenges a dominant view of evidence as quantitative outputs and adds a conceptual approach to evidence of learning that reveals the gradual process of skill growth. An inclusive view of evidence draws on critical reflections that value the qualitative learning of everyday practice. Finally, how we think of evidence affects the robust development of HR competence to influence individual and organizational behaviour.

\section{References}

Boud, D., \& Hager, P. (2012). Re-thinking continuing professional development through changing metaphors and location in professional practices, Studies in Continuing Education, 34(1), 17-30.

Brown, A. (2014). Identity, and Identities Work in Organisations, International Journal of Management Reviews, 17, 20-40.

Chartered Institute of Personnel Development [CIPD] (2012). Code of Professional Conduct. Retrieved from www.cipd.co.uk

Clegg, S. (2003). Problematising ourselves: continuing professional development in higher education, International Journal for Academic Development, 8(1), 37-50.

Coffield, F. (1999). Breaking the Consensus: Lifelong learning as social control, British Educational Research Journal, 25(4), 479-499.

Coles, C. (2002). Developing professional judgement. The Journal of Continuing Education in the Health Professions, 22, 3-10.

Confederation of British Industry (CBI). 2015. Inspiring growth CBI/Pearson Education and Skills Survey. Retrieved from www.http://news.cbi.org.uk/reports/education-and-skills-survey-2015 
Contu, A., \& Willmott, H. (2003). Re-embedding Situatedness: The importance of power relations in learning theory, Organization Science, 14(3), 283-296.

Cunliffe, A. (2010). Crafting Qualitative Research: Morgan and Smircich 30 Years On, Organizational Research Methods, 14(4), 647-673. doi: 10.1177/1094428110373658.

Eraut, M. (2004). Informal learning in the workplace, Studies in Continuing Education, 26(2), 247-273.

Gao, Y., \& Riley, M. (2010). Knowledge and Identity: A Review, International Journal of Management Reviews, 317-334. doi: 10.1111/j.1468-2370.2009.00265.x

Garofano, C., and Salas, E. (2005). What influences continuous employee development decisions? Human Resource Management Review, 15, 281-304.

Hart, A., \& Montague, J. (2015). 'The Constant State of Becoming': Power, Identity, and Discomfort on the Anti-Oppressive Learning Journey. Journal of Psychological Issues in Organizational Culture, 5(4), $39-52$.

Institute of Employment Studies (IES) (2015). HR in a disordered world IES Perspectives on HR. Retrieved from www.employment-studies.co.uk

Institute of Employment Studies (IES) (2016). The Brexit effect on HR. Part One: the immediate issues. Retrieved from http://www.employment-studies.co.uk/resource/brexit-effect-hr-part-one-immediateissues

Kennedy, A. (2014). Understanding continuing professional development: the need for theory to impact on policy and practice, Professional Development in Education, 40(5), 688-697.

Mackay, M. (2015a). Professional development seen as employment capital, Professional Development in Education. doi: 10.1080/19415257.2015.1010015.

Mackay, M. (2015b). Identity formation: professional development in practice strengthens a sense of self, Studies in Higher Education. doi: 10.1080/03075079.2015.1076780.

Mackay, M., \& Tymon, A. (2014). Taking a risk to develop reflective skills in business practitioners, Journal of Education and Work. doi:10.1080/13639080.2014.939160.

McCormick, R. (2010). The state of the nation in CPD: a literature review. The Curriculum Journal, 21(4), 395-412.

McWilliam, E. (2002). Against Professional Development, Educational Philosophy and Theory, 34(3), 289-299.

Morrell, K., \& Learmonth, M. (2015). Against Evidence-Based Management for Management Learning, Academy of Management Learning and Education, 14(4), 520-533.

Organisation for Economic Co-operation and Development (OECD) (2010). Recognising Non-formal and Informal Learning: Outcomes, Policies and Practices. Retrieved from www.oecd.org/education/

Society of Human Resource Management (SHRM) (2007). HR and business education: Building value for competitive advantage. SHRM Research Quarterly 2, 1-10.

Taylor, R. (2009). Lifelong learning under New Labour: an Orwellian dystopia? Power and Education, $1(1), 71-82$.

Thomson I. (2001). Heidegger on Ontological Education, or: How We Become What We Are, Inquiry. An Interdisciplinary Journal of Philosophy, 44(3), 243-268. DOI: 10.1080/002017401316922408

Volles, N. (2014). Lifelong learning in the EU: changing conceptualizations, actors and policies, Studies in Higher Education, DOI: 10.1080/03075079.2014.927852

Wright, C. (2008). Reinventing human resource management: Business partners, internal consultants and the limits to professionalization. Human Relations, 61(8), 1063-1086.

XpertHR (2016). HR Roles and Responsibilities. Retrieved from http://www.xperthr.co.uk

\section{The Author}

Margaret Mackay is a Course Leader and Senior Lecturer for postgraduate human resource management programmes at the University of Portsmouth's Business School. Margaret uses her diverse experience of talent management in the Middle East, Latin America, Europe, and the United States to enrich her teaching and consultancy work. She researches identity, 
leadership skills, reflective learning, and continuous professional development. Recent journal publications, orcid.org/0000-0001-6325-5789, include Studies in Higher Education, Human Resource Development International, Journal of Education and Work, Professional Development in Education, and Teaching in Higher Education. 